$\xi=$ 줄

\title{
Knowledge, attitude and practice of using antibiotics as self-medication among non-medical graduates
}

\author{
Asha V, Karthik D Yadav * \\ The Oxford Dental College, 10th Milestone, Bommanahalli, Hosur Road, Bangalore- 560 102, India \\ *Corresponding author E-mail: karthikyadavd@gmail.com
}

\begin{abstract}
Background: Antibiotic abuse is a major concern in the modern era of internet. The ease of availability of drugs, lack of time to visit a doctor, poverty, the lack of knowledge about antibiotics, the influence of relatives, friends and advertising media seems to be the major contributing factors for self-medication. The objective of the study was to assess the knowledge, attitude and practice of antibiotics as self-medication among non-medical graduates.

Methodology: A validated, self-administered questionnaire on knowledge, attitude and practice was used to collect data from 400 nonmedical graduates.

Results: Statistical analysis was done by Chi-square and Multiple response test. Results revealed that 163(68\%) B.E and 95(59\%) B.Com graduates were aware of antibiotics. Majority of graduates $(>90 \%)$ in both the groups have the opinion that antibiotics are "Over the Counter" (OTC) drugs and that they have adverse effects.

Conclusion: Majority of B.E and B.Com graduates were aware of antibiotics, but not of their side effects. They had the misconception that antibiotics are "OTC" drugs. The most common reason for self-medication was the previous use of same medication.
\end{abstract}

Keywords: Knowledge; Attitude; Practice; Non-Medical Graduates; Self-Medication; Over the Counter (OTC); Antibiotics

\section{Introduction}

Self-medication means consumption of the medicines for illness without a valid prescription. The practice of self-medication is encouraged by "World Health Organization" (WHO) for effective and quick relief of symptoms in rural and remote areas where health care services are understaffed and inaccessible but the adverse effects of self-medication can be severe or sometimes even fatal for life (Nastings JK et al 2006, Mehta R \& Sharma S 2015, Sodhi A et al 2016).

Drugs which are available without a doctor's prescription from the pharmacies are termed as 'nonprescription' or 'OTC drugs. (Mehta R \& Sharma S 2015, Sodhi A et al 2016). Some of the commonly available OTC drugs in India are analgesics, nasal decongestants and antacids. As such antibiotics are not OTC drugs, but it is still used as OTC drugs. The practice of self-medication of antibiotics has led to antibiotic resistance, which is now recognized as a global public health problem with major economic, social and political implications (Alzoubi K et al 2013).

The study evaluated the knowledge, attitude and practice of using antibiotics as self-medication among non-medical graduates.

\section{Materials and methods}

The present study was carried out amongst the engineering and commerce graduates of The Oxford institutions, Bangalore.

\subsection{Method of collection of data}

A subject expert validated questionnaire was distributed to 400 graduates. 238 engineering and 162 commerce students participated in the study. The questionnaire contained questions covering demographic information, knowledge, attitude and practice focusing on antibiotic use without a prescription.

\section{Results}

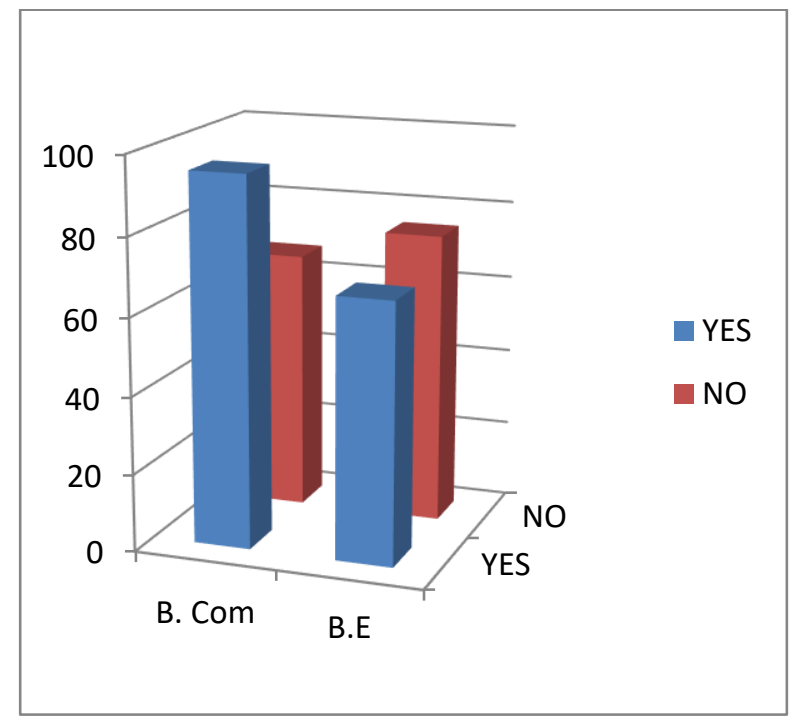


Statistical analysis was performed by chi-square and multiple response test to analyse the data obtained from the study.

Out of 400 participants, $238(59.5 \%)$ were B.E and $162(40.5 \%)$ were B.Com graduates. Results revealed that 163 (68\%) B.E and $95(59 \%)$ B.Com graduates were aware of antibiotics (Fig.1). However, majority of the graduates $(>90 \%)$ have the misconception that antibiotics are "OTC" drugs. They knew that antibiotics have adverse effects, but only $33(20 \%)$ B.E graduates and $15(16 \%)$ B.Com graduates knew about antibiotic resistance, which clearly indicates the lack of knowledge about "antibiotic resistance".

About $90 \%$ graduates from both the groups reported that they had taken antibiotics within the last 3 months. The present study showed that antibiotics was suggested by Parents (44\%), pharmacists $(33.5 \%)$, Friends $(12.5 \%)$. The reasons cited for selfmedication (Table.1) included - same medication used previously, to avoid hassle of going to a doctor, saving money and time, same medication previously used by other members of the family, left over medicine at home

Table 1: Showing the Number of People Taking Self-Medication for Various Reasons

\begin{tabular}{lll}
\hline Why did you choose the antibiotic(s) instead of going to a & B.Co & B \\
Doctor for your complaint(s) & E & N \\
\hline Saves Time & 28 & 36 \\
Saves money & 42 & 66 \\
To avoid the hassle of going to the doctor & 54 & 86 \\
The same medicine successfully resolved my complains & 73 & 11 \\
previously & & 3 \\
Same medicine worked for my friends/family member with & 32 & 47 \\
similar complaints & 25 & 49 \\
Left over medicine was present at home &
\end{tabular}

More than $75 \%$ (B.E) and 60\% (B.Com) graduates neither remembered the medication that was used nor did they remember the duration or frequency of the medication. Antibiotics usage for toothache was reported to be $30 \%$ \& $26 \%$ by B.E \& B.Com graduates respectively.

$92 \%$ graduates reported symptomatic relief after antibiotic usage and $84 \%$ of them believed that they can increase the drug dose by themselves when symptoms are not relieved and also discontinue the medication when there was no symptomatic relief.

The majority $(>80 \%)$ of them believed that the same antibiotics can be used for all types of infections and were also willing to give their prescription to someone else who was having similar symptoms.

\section{Discussion}

The Word "Antibiotic" certainly arises to the mind whenever an infection has to be dealt with. Antibiotics have shown a remarkable stance in the field of medicine. Hence we can term the 20th century of medicine as the "Antibiotic era" (Jain M \& Oswal S 2013, Tripati KD 2003 p 716).

The abuse of antibiotics may lead to more serious consequences than the original illness for which the medication was used. Despite the adverse effects caused by antibiotic use, we cannot ignore antibiotics as they are mankind's most potential weapon against infection (Jain M \& Oswal S 2013, Tripati KD 2003 p 716).

In the present study, majority of B.E and B.Com graduates were aware of antibiotics, but had the misconception that antibiotics are "OTC" drugs. The parents and the pharmacists suggested antibiotics, rather than a certified physician. Even though the intention of the person who suggested the medication was noble, but the adverse effects cannot be ignored. The various reasons for selfmedication in increasing order of frequency was - previous use of same medication, hassle of visiting a doctor, saving money, same medication used by other family members, previous left over medicine(Table 1).
B.E and B.Com Graduates had taken antibiotics within the last 3 months but most of them neither remembered the medication nor the duration or the frequency of use, which reflects the fact that the idea of self-medication was very much influential from other sources.

A majority of them got symptomatic relief from self-medication. Hence this can add a great boost in oneself to the misconception that self-medication is very much effective and safe. This was clearly reflected in our study that $84 \%$ of study population said that they can increase the drug dose by themselves and also that they can discontinue doctor's prescription by themselves, when there was no symptomatic relief

Antibiotics once termed as the "Miracle Drug is now termed as the 'Medicines with the Red Line'. This comes at a time when the consumption of antibiotics in India has increased sharply while the effectiveness of these drugs to treat bacterial infections has been steadily declining. A report in The Lancet Infectious Diseases says that India consumed 13 billion units of antibiotics in 2010, the highest in the world. Between 2005 and 2009, consumption shot up by 40 per cent.

Hence, efforts should stress on interventions including educational programs in the form of lectures, campaigns, workshops, seminars, leaflets and preparation of guides of conditions for which antibiotic use is not suitable. Health authorities should practice more control on pharmacies (Sodhi A et al 2016).

Our study showed that, inadequate knowledge and the indiscriminate use of antibiotics was influenced to a large extent by parents and friends and also the attitude of an individual. Hence, educational intervention should be aimed to make the population conscious of potential risks and dangers linked to self-medication (Sodhi A et al 2016).

A holistic approach must be taken to prevent this problem from escalating which would involve awareness and education regarding the implications of self-medication of antibiotics, strategies to prevent the dispensing of medicines without prescription by pharmacies and to ease the availability of health care(Zafar $\mathrm{S}$ et al 2008).

\section{References}

[1] Sodhi A, Tadiparthi J, Patil BA. Indian J Med Res \& Pharm Sci. July 2016; 3(7).

[2] Mehta R, Sharma S. Knowledge, Attitude and Practice of SelfMedication among Medical Students. IOSR Journal of Nursing and Health Science. 2320-1940 Vol 4, Iss 1, Ver. I (Jan.-Feb. 2015), P.89-96.

[3] Nastings J, Schwananda K, Daniel C, Spadaro et al. Integrating an Elective Self-Care Experience With a Required Advanced Pharmacy Practice Community Experience. $\mathrm{J}$ of pharmaceutical education 2006:70(6).

[4] http://www.pharmaceutical-drugmanufacturers.com/pharmaceutical-drugs/non-prescriptiondrugs.html

[5] Alzoubi K, Al-Azzam S, Alhusban A, Mukattash T, Al-Zubaidy S, Alomari N, Khader Y. An audit on the knowledge, beliefs and attitudes about the uses and side-effects of antibiotics among outpatients attending 2 teaching hospitals in Jordan. EMHJ, Vol.19: No.5 2013.

[6] Jain M, Oswal S. Antibiotics in Dentistry - An Art and Science. Annals of Dental Speciality: 2013; Vol.01, Iss 01

[7] Tripati KD. Textbook of Pharmacology for medical students. 5th ed 2003.

[8] Http://www.thehindu.com/opinion/op-ed/The-antibiotic-red-line-ofcontrol/article14140186.ece.

[9] Zafar S et al. Self-medication amongst University Students of Karachi: Prevalence, Knowledge and Attitudes. J Pak Med Assoc: Vol. 58, No. 4, Apr 2008 